\title{
PODCAST: UMA PROPOSTA DE DESCRIÇÃO POR MEIO DE PADRÕES DE METADADOS
}

\author{
Victória Elisa Barbara de Sousa (Graduanda em Biblioteconomia e Ciência da \\ Informação - UFSCar) \\ Profa. Dra. Ana Carolina Simionato (Orientadora)
}

\section{RESUMO}

Podcast é o termo utilizado para se referir a arquivos de áudio disponibilizados por meio do formato RSS em linguagem XML, podendo ser considerado uma forma de clipping automatizado e contínuo. Sendo caracterizado como recurso informacional devido a dispor de informação objetivada que possui variados formatos e que pode tratar de diversos temas. Classificá-lo e descrevê-lo apenas como um arquivo de áudio, sem considerar as suas particularidades e peculiaridades, faria com que a sua representação fosse inadequada e consequentemente, o seu tratamento, organização e recuperação não seriam amplos e satisfatórios. Logo, se faz necessário a definição dos metadados essenciais de um podcast para que o mesmo possa ser representado integralmente, bem como a identificação de um padrão de metadados que seja adequado para a sua descrição. A realização da pesquisa teórico-aplicada, será feita a partir de uma pesquisa exploratória qualitativa, visando identificar os padrões de metadados que podem ser aplicados a arquivos de áudio, e posteriormente se estabelecerá qual deles melhor atende os requisitos para a representação de podcasts.

Palavras-chave: Podcast. Metadados. Descrição de arquivos de áudio.

O termo metadados foi cunhado por Jack E. Myers na década de 1960 para descrever 'conjunto de dados' e tornou-se mais conhecido pela definição sucinta de 'dados sobre dados'. Amplamente usado não só por profissionais da área da informação, mas por diversas comunidades de profissionais de "[...] diferentes áreas que possuem o mesmo objetivo: dar tratamento aos recursos informacionais tendo em vista o gerenciamento informacional" (SIMIONATO, 2015, p. 71).

Senso e Rosa Piñeros (2003, p. 97, tradução nossa) os metadados são como "[...] toda a informação descritiva sobre o contexto, qualidade, condição ou características de um recurso, dado ou objeto". Condizendo, a NISO (2004, p. 01, tradução nossa), National Information Standards Organization declara que para o ambiente de bibliotecas os metadados são considerados um esquema de descrição formal para qualquer tipo de recurso, digital ou não.

Isto posto, da mesma forma que os catálogos das bibliotecas, a principal finalidade dos metadados é descrever propriedades de arquivos para proporcionar a sua descoberta e localização (ROCHA, 2007, p. 113). Ou ainda, “[...] facilitar a recuperação, autenticação, evolução, preservação e interoperabilidade" (SENSO; ROSA PIÑEROS, 2003, p. 97, tradução nossa). Souza, Catarino e Santos (2012, p. 94) inteiram que a finalidade dos metadados é documentar e organizar de forma estruturada os dados para reduzir a duplicação de esforços. 


\section{SEMINÁRIO DE PESQUISA EM CIÊNCIAS HUMANAS - SEPECH \\ Humanidades, Estado e desafios didático-científicos \\ Londrina, 27 a 29 de julho de 2016}

Senso e Rosa Piñeros (2003, p. 102, tradução nossa) os dividem em cinco tipos: os administrativos (usados para o gerenciamento e administração dos recursos informacionais), os descritivos (usados para representar informações sobre recursos), os de preservação (relacionados à conservação de recursos de informação), os técnicos (relacionados ao funcionamento do sistema e comportamento dos metadados) e os de uso (relacionados com o nível e tipo de uso dos recursos informacionais).

Cabe afirmar que os metadados estão presentes na descrição de recursos informacionais desde antes da web e que, após o surgimento da web 2.0, tiveram seu uso ainda mais presente graças aos relacionamentos que são capazes de estabelecer pelo conceito de Linked Data (dados ligados entre si). Resumidamente os "[...] metadados são indispensáveis para assegurar que os recursos informacionais irão sobreviver e continuar acessíveis no futuro" (NISO, 2004, p.01, tradução nossa). Os padrões são necessários para assegurar a aceitação internacional dos metadados e sua interoperabilidade (SANTOS; SIMIONATO; ARAKAKI, 2014, p. 148). Uma vez que a "[...] estrutura sempre foi importante na representação e organização da informação, mesmo antes da informatização" (GILLILAND, 2008, p. 5, tradução nossa).

São então estruturas de descrição formadas por um conjunto predeterminado de metadados que dão a certeza de uma representação unívoca e padronizada de um recurso que possa ser utilizada para recuperação do mesmo (ALVES, 2005, p. 47). Santos (2013, p. 02) explícita que o seu principal encargo é a possibilidade que dispõem de estabelecer comunicação e compartilhamento de dados entre sistemas que não possuem os mesmos sistemas de hardware e software (interoperabilidade). Logo, Alves (2005, p. 61) destaca que:

[...] o princípio de criação ou a razão da origem do padrão é promover a descoberta de recursos informacionais na Web. Esse princípio norteará as características da estrutura descritiva e consequentemente a representação dela originada.

Por consequência não há um único padrão de metadados que seja adequado para a descrição de todos os tipos de coleções e materiais existentes. Havendo a necessidade de uma seleção do conjunto de padrões de metadados e de ferramentas que se adequem aos recursos informacionais, para ter-se a garantia de uma boa descrição de coleção de materiais específicos, como também a possibilidade de mapear os metadados, promovendo assim a interoperabilidade (GILLILAND, 2008, p. 05, tradução nossa). Se a seleção do conjunto de padrões de metadados não representar plenamente o recurso informacional, poderá acarretar em perca de informações, como também no comprometimento da interoperabilidade, da recuperação e organização do recurso informacional.

Destarte, os podcasts nada mais são do que um som gravado, podendo ser editado, ter a inserção de sons ambientes e/ou músicas e efeitos sonoros, ou não. Considerada a palavra do ano de 2005 pelo New Oxford American Dictionary (PACHECO, 2010, DURRANI; GOTKIN; LAUGHLIN, 2015, tradução nossa), o termo podcast surgiu de um neologismo do sufixo 'casting' (distribuição ou difusão midiática) da palavra inglesa Broadcasting (radiodifusão) com o prefixo 'pod', termo provindo dos tocadores portáteis de arquivos digitais de música ('tocadores de MP3' ou MP3 players), como o iPod da Apple (MEDEIROS, 2006, PRIMO, 2005, LUIZ; ASSIS, 2010).

Durrani, Gotkin e Laughlin (2015, tradução nossa) definem podcast como sendo "[...] a combinação de arquivos de áudio e um sistema de distribuição, o feed RSS, que envia um novo conteúdo para dispositivos portáteis dos membros da audiência automaticamente". Pacheco (2010, p. 09) condiz que o podcast "Permite, graças à tecnologia RSS (Really Simple 


\section{SEMINÁRIO DE PESQUISA EM CIÊNCIAS HUMANAS - SEPECH \\ Humanidades, Estado e desafios didático-científicos \\ Londrina, 27 a 29 de julho de 2016}

Syndication), a distribuição de ficheiros pela Internet, através de uma subscrição, evitando assim que o user ande à procura dos conteúdos constantemente".

Bottentuit Junior e Coutinho (2007, p. 839) entendem podcast como "[...] uma página, site ou local onde os ficheiros áudio estão disponibilizados para carregamento". Moura e Carvalho (2006, p. 01), definem podcast como "[...] a tecnologia utilizada para descarregar conteúdos áudio das páginas $W e b "$.

Barros e Menta (2007) complementam dizendo que os podcasts podem ser assemelhados à um programa rádio gravado em formatos digitais que permitam o armazenamento do áudio em pouco espaço, sendo disponibilizados na $W e b$ vinculados a um arquivo de informação (feed), que permite a atualização automática dos programas.

Primo (2005) afirma que é justamente a distribuição dos podcasts que os diferenciam de um programa de rádio, ou mesmo dos 'audioblogs' (blog em formato de áudio), juntamente com seus mais variados temas e formatos. Após ser gravada a versão final do arquivo de áudio (podendo ser em MP3, ou qualquer outro formato para arquivos de áudio) o podcaster, "[...] indivíduo que produz, ou seja, o autor que grava e desenvolve os ficheiros no formato áudio" (BOTTENTUIT; COUTINHO, 2007, p. 839), envia o arquivo para um servidor e faz upload (envio de dados de um PC para a web) de um arquivo RSS na linguagem XML (um arquivo de texto). Esse texto faz com que 'agregadores' (softwares) saibam quando tem um novo episódio do podcast disponível para download automático.

Bottentuit Junior e Coutinho (2007, p. 839) entendem podcasting como o ato de "[...] gravar ou divulgar os ficheiros na web". Logo, a simples publicação de um arquivo de áudio na internet, não se classifica como podcasting e consequentemente, os arquivos não são caracterizados como podcasts (LUIZ; ASSIS, 2010).

Para Vanassi (2007) um sistema podcasting deve possuir quatro características essenciais relacionadas a sua: Produção, Tipo de Arquivo, Disponibilidade e Acesso. Para se produzir um podcast não é necessário ter um conhecimento avançado, ou equipamentos de alta tecnologia, bastam um computador equipado com microfone, fones de ouvido e uma placa de áudio com capacidade de gravação e reprodução de sons. Os arquivos devem possuir um tamanho que não seja muito grande, para isso são usados formatos de arquivo comprimido. Devem estar disponíveis de maneira pública e de fácil acesso, já que o ouvinte deve conseguir baixar e ouvir os programas disponibilizados a qualquer hora, para isso há a necessidade de os arquivos serem hospedados em servidores ligados à internet. E por último devem fazer uso da tecnologia RSS.

Pode-se considerar o podcast como uma forma de clipping (disseminação seletiva da informação digital) automatizado e contínuo, que permite ao usuário a escolha do que deseja receber. Isto posto, pode-se classificá-lo em vários modelos diferentes, Medeiros (2009) aponta três deles:

- O modelo 'Metáfora', possui características parecidas a de um programa de rádio, tendo um apresentador, blocos musicais, vinhetas, notícias, entrevistas, etc. Foi o primeiro modelo criado.

- O modelo 'Editado' são os próprios programas da rádio editados e disponibilizados após sua transmissão pela própria emissora.

- O modelo 'Registro' assemelha-se aos 'audioblogs'.

Além desses, pode-se identificar mais um modelo de podcast, o modelo de 'Storytelling', que pode ser traduzido como o ato de contar uma história por meio da utilização de palavras ou recursos audiovisuais para transmitir uma história, verídica ou não. Neste caso os podcasters estão fazendo uso de uma técnica já existente para divulgarem seu trabalho por meio da contação de histórias, sendo de improviso ou treinadas. 


\section{SEMINÁRIO DE PESQUISA EM CIÊNCIAS HUMANAS - SEPECH \\ Humanidades, Estado e desafios didático-científicos \\ Londrina, 27 a 29 de julho de 2016}

Como um posdcast do modelo Metáfora, tem-se o AntiCast (MIZANZUK; ANCARA; BECCARI, 2016), trata de cultura, literatura, filosofia e design. É apresentado no formato de conversa entre os convidados e o(s) host(s) (anfitrião) de cada episódio. Do modelo Editado, um bom exemplo é o programa da rádio Bandeirantes, $\mathrm{O}$ Pulo do Gato (RÁDIO BANDEIRANTES, 2016). Ele leva ao ar as manchetes das principais notícias do dia e é o programa recordista de permanência no ar, no rádio brasileiro (mesma emissora, mesmo horário e mesmo apresentador). O podcast O Nome Disso é Mundo (2016), pode ser considerado um exemplo do modelo Registro. Ele é um podcast de entrevistas com brasileiros expatriados, que compartilham suas experiências fora do Brasil.

Como exemplo do modelo de Storytelling tem-se o podcast Welcome to Night Vale (FINK; CRANOR, 2016, tradução nossa), ele é narrado como uma rádio da cidade do deserto fictícia de Night Vale, onde são apresentadas atualizações quinzenais sobre o clima, noticias, anúncios da polícia secreta, luzes misteriosas no céu da noite, figuras encapuzadas, escuros locais com poderes incognoscíveis e eventos culturais.

Os podcasts são armazenados usualmente em catálogos, ou plataformas de publicação de arquivos de áudio, como a biblioteca de música da Apple, o iTunes, e a plataforma SoundCloud. Também podem ser encontrados nas bibliotecas dos aplicativos 'agregadores' de podcasts e em seus buscadores (BOULOS; WHEELERT, 2007, tradução nossa).

Visto o escopo dessa pesquisa, os podcasts são representados pelos padrões de metadados do domínio sonoro. Sendo ele, considerado uma vertente do domínio audiovisual, combinação de som e imagem, Bethônico (2006, p. 61) define:

[...] qualquer suporte onde possa se estabelecer alguma relação audiovisual. Linguagem audiovisual é um sistema de signos com determinados processos de articulação e de significação, com uma gama de sentido que os mesmos signos possuem dentro do sistema e com um conjunto pertinente de relações entre seus componentes visuais e sonoros.

Não obstante, Rodríguez (2006, p. 27) diz que a linguagem audiovisual pode ser entendida como:

[...] os modos artificiais de organização da imagem e do som que utilizamos para transmitir ideias ou sensações ajustando-nos à capacidade do ser humano para percebê-las e compreendê-las, e não cada um dos meios tecnológicos que utilizam essa linguagem.

Ou ainda, um conjunto de recursos expressivos, previamente imaginados por um narrador, que permitem estimular sensações e percepções no público que se transformarão em mensagens complexas e concretas. Dando forma a um emaranhado complexo no qual convergem música e língua (tanto oral como escrita) (RODRÍGUEZ, 2006, p. 28). Assim:

[...] na linguagem audiovisual se articulam perfeitamente a língua e a música como sistemas de códigos complexos que se entrelaçam com as simulações perceptivas naturalistas características do desenho, da pintura, da fotografia, das montagens com imagem fixa e som, do cinema, do rádio, da televisão, etc., transferindo-lhe sua própria capacidade expressiva. (RODRÍGUEZ, 2006, p. 28). 


\section{SEMINÁRIO DE PESQUISA EM CIÊNCIAS HUMANAS - SEPECH \\ Humanidades, Estado e desafios didático-científicos \\ Londrina, 27 a 29 de julho de 2016}

Ferreira (2015, p. 19) afirma que a "[...] informação sonora é um elemento especifico e autônomo, sendo possível encontrá-la independente e sozinha enquanto forma de expressão e ou associada com as expressões visuais". À vista disso, a vertente sonora do domínio audiovisual trabalha diretamente com recursos informacionais onde apenas o som/áudio está presente, e seu conteúdo não possui qualquer representação imagética. Nascimento (2008, p. 06) define áudio como sendo vibrações do ar, sendo o recurso informacional de áudio o registro feito dessas vibrações. Já Rodríguez (2006, p. 53) afirma que o som:

[...] resulta da percepção auditiva de variações oscilantes de algum corpo físico, normalmente através do ar. A origem de um som é sempre a vibração de um objeto físico, dentro da gama de frequências e amplitudes que o ouvido humano é capaz de perceber. Essa vibração empurra ritmadamente as moléculas dos outros corpos físicos que o rodeiam, provocando, por sua vez, vibrações nessas moléculas. Quando essas vibrações chegam a nosso ouvido, normalmente através do ar, são percebidas como um som. Em suma, o fenômeno sonoro é a percepção das oscilações rítmicas, normalmente da pressão do ar, que foram estimuladas por outro objeto físico vibrante, que atua como fonte de emissão.

Pode-se afirmar que áudio e som são apenas termos diferentes para descrever um fenômeno físico, uma vibração no ar que é percebida pelo nosso complexo sistema auditivo. Sendo o ato de ouvir algo sem a visualização de sua fonte sonora é definido como 'acusmático', tendo o termo se originado de uma metodologia pedagógica de Pitágoras, onde seus alunos ouviam suas aulas atrás de uma cortina, para desassociar a imagem do narrador, a fonte física da narração, do som emitido (FERREIRA, 2015, RODRÍGUEZ, 2006).

Por meio do avanço da tecnologia que permite gravar e armazenar o som, não há mais a necessidade de se estar perto do transmissor, ou que ele esteja escondido para que haja a dissociação da narração com a imagem do narrador, como também não há mais a necessidade de que a transmissão e recepção do som ocorra no mesmo espaço ou tempo. Rodríguez (2006, p. 55) afirma que "A tecnologia do áudio permite-nos tratar o som como um fenômeno passível de ser empacotado, separado e reproduzido de forma completamente independente do objeto físico que o gerou".

Ainda que todos estes padrões permitam a representação única dos recursos informacionais de áudio eles possuem diferenças e particularidades, visto que foram criados em momentos diferentes e até para propósitos diferentes. Riley (2010a, tradução nossa) elaborou um glossário dos padrões de metadados, onde há uma breve descrição de vários metadados. Os padrões de metadados sonoros podem ser exemplificados por: Audio Decision List (ADL), AES Core Audio, AES Process History, Dublin Core Metadata Element Set (DC), ID3, Music Encoding Initiative (MEI), Metadata Encoding and Transmission Standard (METS), MPEG-21 Digital Item Description Language (MPEG-21 DIDL), MPEG Multimedia Content Description Interface (MPEG-7, Material Exchange Format (MXF), Public Broadcasting Core Metadata Dictionary (PB Core), Qualified Dublin Core (QDC) e XML Schema. Definidos por Riley (2010b, tradução nossa) no infográfico Seeing Standards: A Visualization of the Metadata Universe, como os padrões de metadados que descrevem de forma mais satisfatória os materiais musicais. A seguir, no quadro 1, os padrões de metadados indicados para materiais musicais serão descritos. 


\section{SEMINÁRIO DE PESQUISA EM CIÊNCIAS HUMANAS - SEPECH \\ Humanidades, Estado e desafios didático-científicos \\ Londrina, 27 a 29 de julho de 2016}

\begin{tabular}{|c|c|c|}
\hline $\begin{array}{l}\text { Padrão de } \\
\text { Metadados }\end{array}$ & Sigla & Descrição \\
\hline $\begin{array}{l}\text { Audio } \\
\text { Decision List - } \\
\text { AES31-3 }\end{array}$ & ADL & $\begin{array}{l}\text { Padrão para a rede em para a transferência de arquivos de } \\
\text { áudio - É um formato de arquivo baseado em texto e um } \\
\text { padrão de metadados para codificar os resultados da ação de } \\
\text { edição de áudio. O formato registra cortes, degradações, os } \\
\text { resultados de processamento e filtragem, e outras edições em } \\
\text { arquivos de áudio feitas por um engenheiro de som. }\end{array}$ \\
\hline $\begin{array}{l}\text { AES Core } \\
\text { Audio } \\
\text { AES-X098B }\end{array}$ & & $\begin{array}{l}\text { Metadados descritivos para objetos sonoros - Esquema de } \\
\text { áudio central - O escopo do padrão é amplo e contempla } \\
\text { analógicos originais, cópias reformatadas digitalmente e } \\
\text { gravações nativas digitais. A especificação permite a captura } \\
\text { de propriedades básica do áudio. }\end{array}$ \\
\hline $\begin{array}{l}\text { AES Process } \\
\text { History - AES- } \\
\text { X098C }\end{array}$ & & $\begin{array}{l}\text { Metadados administrativos para objetos sonoros - Esquema de } \\
\text { processo histórico - É um dicionário de dados e Esquema } \\
\text { XML para gravar informações sobre os processos que têm sido } \\
\text { realizados em arquivos de áudio ao longo do tempo. Inclui } \\
\text { estruturas de campo para descrever e fornecer acesso ao } \\
\text { conteúdo de áudio contidos em arquivos digitais. Permite a } \\
\text { transferência, a preservação e restauração da informação. }\end{array}$ \\
\hline $\begin{array}{l}\text { Dublin Core } \\
\text { Metadata } \\
\text { Element Set }\end{array}$ & $\mathrm{DC}$ & $\begin{array}{l}\text { É um conjunto básico de quinze elementos concebidos para } \\
\text { representar as características fundamentais de todos os } \\
\text { formatos de recursos. }\end{array}$ \\
\hline ID3 & ID3 & $\begin{array}{l}\text { São dados armazenados dentro de um arquivo de áudio MP3 } \\
\text { para ajudar na identificação do conteúdo do arquivo. ID3v2 } \\
\text { inclui uma série de "frames" predefinidos (campos essenciais) } \\
\text { para uso, incluindo o título do álbum, compositor, data de } \\
\text { gravação, artista e proprietário. }\end{array}$ \\
\hline $\begin{array}{l}\text { Music } \\
\text { Encoding } \\
\text { Initiative }\end{array}$ & MEI & $\begin{array}{l}\text { É uma linguagem de marcação para notação de música comum } \\
\text { ocidental. Feito para facilitar a pesquisa dentro da estrutura do } \\
\text { corpus musical. Inclui um cabeçalho para informações } \\
\text { bibliográficas sobre o arquivo de notação. }\end{array}$ \\
\hline $\begin{array}{l}\text { Metadata } \\
\text { Encoding and } \\
\text { Transmission } \\
\text { Standard }\end{array}$ & METS & $\begin{array}{l}\text { É um padrão de metadados XML e destina-se empacotar todas } \\
\text { as informações necessárias para representar um objeto } \\
\text { complexo, incluindo os arquivos primários e metadados que os } \\
\text { descrevem. Ele define sua própria estrutura para representar } \\
\text { arquivos e as relações entre eles, e permite a incorporação ou } \\
\text { referência descritiva, técnicas, direitos, fonte e metadados } \\
\text { proveniência digitais definida por outros esquemas. }\end{array}$ \\
\hline
\end{tabular}




\section{SEMINÁRIO DE PESQUISA EM CIÊNCIAS HUMANAS - SEPECH \\ Humanidades, Estado e desafios didático-científicos \\ Londrina, 27 a 29 de julho de 2016}

\begin{tabular}{|c|c|c|}
\hline $\begin{array}{l}\text { MPEG-21 } \\
\text { Digital Item } \\
\text { Description } \\
\text { Language }\end{array}$ & $\begin{array}{l}\text { MPEG- } \\
21 \\
\text { DIDL }\end{array}$ & $\begin{array}{l}\text { É um formato de embalagem para objetos digitais, definindo } \\
\text { um modelo de dados para representar ambos os arquivos de } \\
\text { conteúdo e seus metadados, e um formato de embalagem XML } \\
\text { que está em conformidade com o modelo de dados DIDL. O } \\
\text { modelo de dados DIDL descreve recipientes, que podem } \\
\text { possuir Itens, com grupos de componentes, grupos individuais } \\
\text { de fluxo de dados, chamados de recursos. Descritores são } \\
\text { aplicados em recipientes, itens ou recursos. }\end{array}$ \\
\hline $\begin{array}{l}\text { MPEG } \\
\text { Multimedia } \\
\text { Content } \\
\text { Description } \\
\text { Interface }\end{array}$ & $\begin{array}{l}\text { MPEG- } \\
7\end{array}$ & $\begin{array}{l}\text { É um padrão para a descrição do conteúdo de arquivos } \\
\text { multimídia, em vez de um formato para os arquivos multimídia } \\
\text { em si. Destina-se a fornecer estruturas de dados, tanto para os } \\
\text { usuários humanos quanto para máquinas. O padrão fornece } \\
\text { "esquemas de descrição" para uma ampla variedade de usos. } \\
\text { Além das descrições de alto nível de conteúdo que permitirá } \\
\text { pesquisar e navegar, há esquemas de descrição para o processo } \\
\text { de criação, informação sobre direitos, informações técnicas, } \\
\text { história de usuário e recursos de baixo nível, tais como cor, } \\
\text { nível de iluminação, e timbre de som. }\end{array}$ \\
\hline $\begin{array}{l}\text { Material } \\
\text { Exchange } \\
\text { Format }\end{array}$ & MXF & $\begin{array}{l}\text { É uma embalagem para um grande conjunto de formatos de } \\
\text { áudio e vídeo digitais mantidos pelo organismo de } \\
\text { normalização Society of Motion Picture and Television } \\
\text { Engineers (SMPTE). O principal objetivo é a troca de objetos } \\
\text { digitais e seus metadados de atendimento entre os dispositivos } \\
\text { de áudio e vídeo, como câmeras e pacotes de edição de vídeo. } \\
\text { Se concentra mais fortemente em recursos de baixo nível de } \\
\text { áudio e vídeo. }\end{array}$ \\
\hline $\begin{array}{l}\text { Public } \\
\text { Broadcasting } \\
\text { Core Metadata } \\
\text { Dictionary }\end{array}$ & PB Core & $\begin{array}{l}\text { É uma extensa estrutura de metadados apoiando a descrição e } \\
\text { troca de ativos de mídia na comunidade de radiodifusão } \\
\text { pública. Os seus elementos são divididos em seções com foco } \\
\text { em conteúdo intelectual, a propriedade intelectual, } \\
\text { instanciações e extensões. }\end{array}$ \\
\hline $\begin{array}{l}\text { Qualified } \\
\text { Dublin Core }\end{array}$ & QDC & $\begin{array}{l}\text { É uma extensão do Simple Dublin Core através do uso de } \\
\text { elementos adicionais, elementos refinamentos e esquemas de } \\
\text { codificação. Dublin Core qualificado é visto em } \\
\text { implementações muito diferentes, muitas vezes usando } \\
\text { refinamentos localmente definidos e esquemas de codificação. } \\
\text { É a base para a maior parte da atividade recente na Iniciativa } \\
\text { de metadados Dublin Core, fornecendo as propriedades } \\
\text { fundamentais que são utilizados nos conjuntos de descrições } \\
\text { em conformidade com o Dublin Core Abstract Model. }\end{array}$ \\
\hline
\end{tabular}




\section{SEMINÁRIO DE PESQUISA EM CIÊNCIAS HUMANAS - SEPECH \\ Humanidades, Estado e desafios didático-científicos \\ Londrina, 27 a 29 de julho de 2016}

\begin{tabular}{|l|l|l|}
\hline & & $\begin{array}{l}\text { Serve como uma alternativa para DTD e RelaxNG como um } \\
\text { método para definir uma linguagem XML para uma finalidade } \\
\text { específica. A linguagem W3C XML Schema permite a } \\
\text { especificação de elementos e atributos, a ordem em que os } \\
\text { elementos podem ser exibidos, cardinalidade de elementos e } \\
\text { atributos, tipos de dados para elementos e atributos, e o uso de } \\
\text { elementos e atributos de outros espaços de nomes. } \\
\text { Documentos W3C XML Schema são expressos em XML. }\end{array}$ \\
\hline
\end{tabular}

Quadro 1 - Glossário de metadados para materiais musicais

Visto a descrição dos padrões de metadados que se aplicam para arquivos sonoros é possível identificar a aplicação que é dada para cada um deles. O padrão de metadados ADL pode ser considerado um padrão de metadados automático, não sendo usado por catalogadores. Já os demais padrões são utilizados conforme a escolha e necessidades dos ambientes informacionais.

Um ambiente informacional que possua analógicos originais seria indicado a utilização do padrão AES Core Audio, ou se fosse necessário ter conhecimento do histórico do recurso informacional de áudio seria indicado o uso do padrão AES Process History. Alguns desses padrões são mais específicos com níveis de descrições complexos e outros são mais genéricos e possuem um esquema de descrição amplo que abrangem não só arquivos sonoros, mas também outros tipos de arquivos, como é o caso do padrão DC.

\section{REFERÊNCIAS}

ALVES, R. C. V. Metadados como elementos do processo de catalogação. 2010. 132 f. Tese (Doutorado em Ciência da Informação) - Faculdade de Filosofia e Ciências, Universidade Estadual Paulista "Júlio de Mesquita Filho", Marília, 2010. Disponível em: $<$ http://hdl.handle.net/11449/103361>. Acesso em: 25 abril 2016.

BARROS, G. C.; MENTA, E. Podcast: produções de áudio para educação de forma crítica, criativa e cidadã. Revista Eptic, v. 9, n. 1, 2007. Disponível em: $<$ http://www.seer.ufs.br/index.php/eptic/article/view/217>. Acesso em: 09 abr. 2016

BETHÔNICO, J. Signos audiovisuais e ciência da informação: uma avaliação. Encontros Bibli: revista eletrônica de biblioteconomia e ciência da informação, Florianópolis, v. 11, n. 2, p. 58-78, 2006. Disponível em: $<$ https://periodicos.ufsc.br/index.php/eb/article/viewArticle/370>. Acesso em: 15 maio 2016.

BOTTENTUIT JUNIOR, J. B.; COUTINHO, C. P. Podcast em Educação: um contributo para o estado da arte. In: IX Congresso Internacional Galego Português de Psicopedagogia, 2007, A Coruña. Revista Galego-Portuguesa de Psicoloxía e Educación., 2007. v. 1. p. 837-846. Disponível em: <http://hdl.handle.net/1822/7094>. Acesso em: 25 abr. 2016.

BOULOS, M. N.; WHEELER, S. The emerging Web 2.0 social software: an enabling suite of sociable technologies in health and health care education. Health Information \& Libraries Journal, England, v. 24, n. 1, p. 2-23, 2007. Disponível em: < 


\section{SEMINÁRIO DE PESQUISA EM CIÊNCIAS HUMANAS - SEPECH \\ Humanidades, Estado e desafios didático-científicos \\ Londrina, 27 a 29 de julho de 2016}

http://onlinelibrary.wiley.com/doi/10.1111/j.1471-1842.2007.00701.x/full>. Acesso em: 10 abr. 2016.

DURRANI, M.; GOTKIN, K.; LAUGHLIN, C. Serial, seriality, and the possibilities for the podcast format. American Anthropologist, v. 117, n. 3, p. 1-4, 2015. Disponível em: < http://onlinelibrary.wiley.com/doi/10.1111/aman.12302/full>. Acesso em: 30 abril 2016.

FERREIRA, J. B. Recuperação de Informação de Música e dados ID3: possíveis aplicações. 2015. 62 f. Dissertação (Mestrado em Ciência da Informação) - Faculdade de Filosofia e Ciências, Universidade Estadual Paulista "Júlio de Mesquita Filho", Marília, 2015. Disponível em: <http://hdl.handle.net/11449/132089>. Acesso em: 15 maio 2016.

FINK, J.; CRANOR, J. Welcome to Night Vale. 2016. Disponível em: $<$ http://www.welcometonightvale.com/>. Acesso em: 16 abr. 2016.

FUSCO, E. Aplicação dos FRBR na modelagem de catálogos bibliográficos digitais. São Paulo: Cultura Acadêmica, 2011. Disponível em: $<$ http://www.culturaacademica.com.br/catalogo-detalhe.asp?ctl_id=168> Acesso em: 21 mar. 2016.

GILLILAND, A. J. Setting the stage. In: BACA, M. (Ed.). Introduction to metadata. 2. ed. Los Angeles: Getty Research Institute, 2008. Cap. 1. p. 1-19.

GLUSHKO, R. et al. Resource description and metadata. In: GLUSHKO, R. (Ed.). The discipline of organizing. California: O’Reilly Media, 2014. Cap. 4. p. 139-187.

LUIZ, L; ASSIS, P. O podcast no Brasil e no mundo: um caminho para a distribuição de mídias digitais. In: CONGRESSO BRASILEIRO DE CIÊNCIAS DA COMUNICAÇÃO, 33. 2010, Caxias do Sul. Anais... São Paulo: Intercom, 2010. Disponível em: < http://www.intercom.org.br/papers/nacionais/2010/resumos/R5-0302-1.pdf > . Acesso em: 09 abr. 2016.

MEDEIROS, M. Transmissão sonora digital: modelos radiofônicos e não radiofônicos na comunicação contemporânea. Ciberlegenda, n. 21, p. 1-17, 2009. Disponível em: $<$ http://www.ciberlegenda.uff.br/index.php/revista/article/view/15>. Acesso em: 10 abr. 2016.

MIZANZUK, I.; ANCARA, R.; BECCARI, M. Anticast. 2016. Disponível em: $<$ http://www.b9.com.br/podcasts/anticast/>. Acesso em: 16 abr. 2016.

MOURA, A.; CARVALHO, A. A. A. Podcast: uma ferramenta para usar dentro e fora da sala de aula. In: Conference on Mobile and Ubiquitous Systems, 2006, Braga. Anais eletrônicos... Braga: Universidade do Minho, 2006. Disponível em: <http://hdl.handle.net/11328/476>. Acesso em: 09 abr. 2016

NASCIMENTO, L. U. Um padrão de metadados para indexação e recuperação de objetos multimídia. 2008. 85 f. Dissertação (Mestrado em Informática) - Setor de Ciências Exatas, Universidade Federal do Paraná, Curitiba, 2008. Disponível em: $<$ http://acervodigital.ufpr.br/handle/1884/24279>. Acesso em: 15 maio 2016. 


\section{SEMINÁRIO DE PESQUISA EM CIÊNCIAS HUMANAS - SEPECH \\ Humanidades, Estado e desafios didático-científicos \\ Londrina, 27 a 29 de julho de 2016}

NISO, National Information Standards Organization. Understanding Metadata. USA: Niso Press, 2004. 16 p. Disponível em: <http://www.niso.org>. Acesso em: 21 mar. 2016.

O nome disso é mundo. O nome disso é mundo. 2016. Disponível em: $<$ http://www.onomedissoemundo.com/>. Acesso em: 16 abr. 2016.

PACHECO, M. I. R. A rádio na internet: do "on air" para o "online". Estudo de caso do serviço público e o caminho para o futuro. 2010. 100 f. Dissertação (Mestrado em Novos Media e Práticas Web) - Faculdade de Ciências Sociais e Humanas, Universidade Nova de Lisboa, Lisboa, 2010. Disponível em: <http://hdl.handle.net/10362/4661>. Acesso em: 05 abr. 2016.

PRIMO, A. F. T. Para além da emissão sonora: as interações no podcasting. Intexto: revista do mestrado da comunicação UFRGS. Porto Alegre, n. 13, p. 1-17, 2005. Disponível em: $<$ http://hdl.handle.net/10183/26568>. Acesso em: 09 abr. 2016.

RÁDIO BANDEIRANTES. O Pulo do Gato. 2016. Disponível em: $<\mathrm{http}$ ://radiobandeirantes.band.uol.com.br/sobre.asp?PDT=28\&ID=91>. Acesso em: 16 abr. 2016.

RILEY, J. Glossary of metadata standards. 2010. Disponível em: $<$ http://jennriley.com/metadatamap/>. Acesso em: 27 maio 2016.

RILEY, J. Seeing standards: a visualization of the metadata universe. 2010. 1 Infográfico. Disponível em: <http://jennriley.com/metadatamap/>. Acesso em: 27 maio 2016.

ROCHA, R. P. Metadados, web semântica, categorização automática: combinando esforços humanos e computacionais para a descoberta e uso dos recursos da web. Em Questão, v. 10, n. 1, 2007. Disponível em: < http://seer.ufrgs.br/index.php/EmQuestao/article/view/86 >. Acesso em: 30 mar. 2016.

RODRÍGUEZ, Á. A dimensão sonora da linguagem audiovisual. São Paulo: Editora Senac São Paulo, 2006. 344 p.

SANTOS, P. L. V. A. C.; SIMIONATO, A. C.; ARAKAKI, F. A. Definição de metadados para recursos informacionais: apresentação da metodologia BEAM. Informação \& Informação, Londrina, v. 19, n. 1, 146 p., 2014. Disponível em: $<$ http://www.uel.br/revistas/wrevojs246/index.php/informacao/article/view/15251>. Acesso em: 25 mar. 2016.

SENSO, J. A.; ROSA PIÑERO, A. El concepto de metadato: algo más que descripción de recursos electrónicos. Ciência da Informação, Brasília, v. 32, n. 2, p. 95-106, 2003.

SIMIONATO, A. C. Modelagem conceitual DILAM: princípios descritivos de arquivos, bibliotecas e museus para o recurso imagético digital. 2015. 200 f. Tese (Doutorado em Ciência da Informação)-Faculdade de Filosofia e Ciências, Universidade Estadual Paulista, Marília, 2015. Disponível em: <http://hdl.handle.net/11449/123318>. Acesso em: 21 mar. 2016. 


\section{SEMINÁRIO DE PESQUISA EM CIÊNCIAS HUMANAS - SEPECH \\ Humanidades, Estado e desafios didático-científicos \\ Londrina, 27 a 29 de julho de 2016}

SOUZA, T. B.; CATARINO, M. E.; SANTOS, P. C. Metadados: catalogando dados na Internet. Transinformação, v. 9, n. 2, 2012. Disponível em: < http://periodicos.puccampinas.edu.br/seer/index.php/transinfo/article/view/1586>. Acesso em: 29 mar. 2016.

VANASSI, G. C. Podcasting como processo midiático interativo. 2007. 69 f. TCC (Graduação em Publicidade e Propaganda) - Curso de Comunicação Social, Universidade de Caxias do Sul, Caxias do Sul, 2007. Disponível em: < http://bocc.ufp.pt/pag/vanassi-gustavopodcasting-processo-midiatico-interativo.pdf>. Acesso em: 10 abr. 2016. 